\title{
Air Pollution and Cultural Heritage: Searching for "The Relation Between Cause and Effect"
}

\author{
Eleni Metaxa \\ School of Chemical Engineering, National Technical University of Athens,
}

Greece

\section{Introduction}

Pollution of the natural environment is largely unintended and unwanted consequences of human activities in manufacturing, transportation, agriculture and waste disposal. High levels of pollution are largely a consequence of industrialization, urbanization and the rapid increase of human population in modern times. Pollutants are commonly classified according to the part of the environment primarily effected by them, either by air, water or land. Sub-grouping depends on characteristics of the pollutants themselves: chemical, physical, thermal and others. Many pollutants affect more than one resource. The substances that pollute the atmosphere are either gases, finely divided soils, or finely dispersed liquids aerosols. Five major classes of pollutants are discharged into the air: carbon monoxide, sulphur oxides, hydrocarbons, nitrogen oxides and particulates (dust, ash). The principle source of air pollution is the burning of fossil fuels, e.g., coal, oil and derivatives of the latter, such as gasoline, in internal combustion engines or for heating or industrial purposes.

The term heritage was used for first time from experts in the early seventies, to declare all the human creation with artistic features, which have been delivered to us as hereditary asset, namely as heritage. At the end of the same decade, the term heritage acquired collective sense and it was used to talk about European Heritage or later about Universal Heritage; in any case to indicate monuments, objects and places.

If in a sense culture is the evolution of human life in space and time, the "monumentsremnants" of the human creation of all the times form the prints, the signs, the evidences, the strides of the human-beings progress within the time: "past narrates its history...". Thus, monuments form an undivided entirety with time and place, with man, his surroundings and his history. These unique and unprecedented fingerprints of human civilization form the natural and cultural heritage of a place, of a country, of a people, the peculiar features of a nation which characterize its identity.

Cultural heritage is continuously undergoing numerical strains: anthropogenic and natural ones, from which the former can be anticipated or/and prevented, whereas the latter not. The result of these strains is the deterioration of all the materials. In fact, there is no material which is not to be downgraded. The Second Law of Thermodynamics inevitably intervenes and finally results in the deterioration of all the materials. For this reason, materials' deterioration is independent, in practice, on their surroundings and it is taking place in any environment, even without the direct contact of the materials with the constituents of a 
corrosive environment. Of course, the environment impacts quantitatively the deterioration or corrosion phenomenon taking place, by means of the impact on the rate of the deterioration process(es) and the kind of the produced substances.

Air pollution as an anthropogenic reason for materials' deterioration forms a problem of a great importance, because it has catastrophic consequences, universally, in health, in the environment and in the cultural heritage monuments and artifacts. The most famous kind of atmospheric pollution is the photochemical cloud, whose components are complicated chemical reactions in atmosphere, which have as principal reactants the hydrocarbons, nitrogen oxides, sulphur oxides, ozone and ultraviolet radiation.

The conservation of works of art and antiquities is intended to: (a) the preservation of cultural heritage, (b) the deceleration of their deterioration processes and (c) the restoration, in some cases, of their form in order to be comprehensible from the public. All of these purposes can be achieved with: (i) control of the environment, (ii) saving static interferences on the monument (i.e., structural conservation), which restore the static sufficiency of the monument, so it does not collapse; (iii) saving interferences on the surface of the monument (i.e., surface conservation), since all decay actions start from the surface of the monument. As the Nobel prize-winners Wolfgang Pauli and Enrico Fermi have felicitously worded: "if God made solids, surfaces were work of Devil"! Indeed, solid surfaces are not uniform, namely homogeneous, but they present heterogeneity, which in general arises from the existence of "imperfections" of various origins. These imperfections are distributed randomly on the surface of the solid material influencing its potential.

An absolutely serious scientific approach of the problem of confrontation of historic buildings and monuments decay because of air pollution presupposes the finding of the relation between "cause and effect", namely of "how and why air-pollutants interact with each other and with the solid surfaces". Then someone could interfere and inhibit a corruptive action on them, by restricting even minimizing the conditions are being responsible for. A scientific answer in the previous question presupposes knowledge of the mechanism of materials surfaces deterioration due to polluted surrounding atmosphere.

\section{A scientific approach to the problem of cultural heritage deterioration due to air pollution}

In order to study the action of air pollutants on cultural heritage monuments is important not only to obtain results by pure chemical analysis of monuments but also to clarify the mechanism of this action. This mechanism may consist of various steps in series, which are usually rate processes, with the deposition as the first step, or sometimes equilibrium states, such as the distribution of air pollutant(s) between the solid surface and the nearby atmospheric environment through adsorption-desorption phenomena. Thus, a simulation of various physicochemical actions of air pollutant(s) on the solid surface must be done followed by the experimental determination of various physicochemical parameters pertaining to the adsorption-desorption phenomena and possible surface heterogeneous reactions constants as well. A schematic representation of the possible physicochemical actions taking place between air pollutant(s) and monuments surface could be the following one: 
convection and diffusion currents of gaseous pollutants

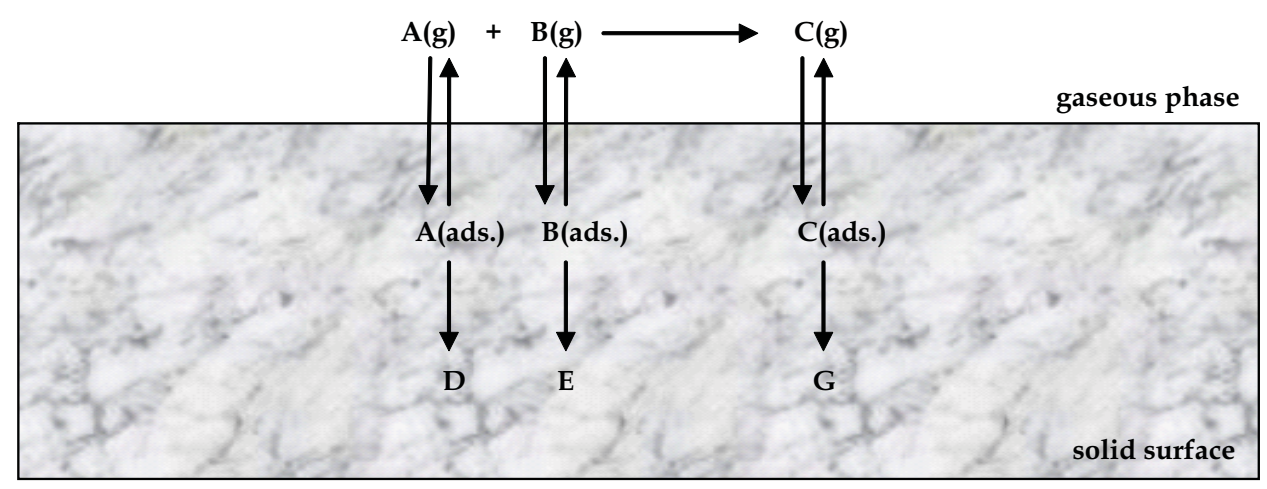

Fig. 1. A model describing the action of air pollutants with the surface of the monument

The model in Fig. 1 is based on the general concept of an open system, consisting of the exposed solid surface, above the which convection currents and diffusion currents as well are causing the transport of the gaseous pollutants $\mathrm{A}(\mathrm{g})$ and $\mathrm{B}(\mathrm{g})$ parallel and perpendicular to the solid surface, while a possible simultaneous interaction between them may produce another gaseous pollutant $\mathrm{C}(\mathrm{g})$, which may be also adsorbed onto the solid surface or/and desorbed back to the gaseous phase, or to be undergone a surface heterogeneous reaction, e.g. dissociation or isomerization. As soon as gaseous pollutants $\mathrm{A}(\mathrm{g})$ and $\mathrm{B}(\mathrm{g})$ are nearing the solid surface, adsorption phenomena are taking place, followed either by a surface chemical reaction between the adsorbed species producing $\mathrm{D}$ and $\mathrm{E}$, or a desorption of them back to the gaseous phase. Therefore, the rate processes describing the above phenomena are the following ones: (i) diffusion of the pollutants from the gaseous to the solid surface, (ii) adsorption of them onto the solid surface, (iii) a possible surface heterogeneous reaction and (iv) desorption of the pollutants back to the gaseous phase.

Therefore an estimation of the crucial relations between environmental factors and materials' deterioration cannot only based on simple measurements of various physicochemical quantities which are validating the materials' decay, but also "timeresolved measurements" are necessary to be done, since only the latter can give information about the actual mechanism of materials' decay. The latter has, in fact, a "local" character, in the sense that it depends on the active sites of the solid surface which are available for adsorption at any particular time $t$. The achievement of this purpose could be done by using a dynamic experimental methodology, which could supply us with "real-time" measurements concerning the whole physicochemical phenomena taking place. To this direction, the novel method of the Reversed-Flow Inverse Gas Chromatography (RF-IGC) has already been successfully applied for various interacting systems gas-solid material or/and gas1/gas2-solid (e.g., gas=HCs, $\mathrm{NO}_{x}, \mathrm{SO}_{x}, \mathrm{O}_{3}$, etc. and solid=a marble sample, a ceramic, a pigment, etc.). The results of these applications of RF-IGC in the investigation of the deterioration mechanism of cultural heritage caused by air-pollutants have already been published in high impact factor International Scientific Journals and reported in Scientific Symposiums both in Greece and abroad as well. 


\section{A brief overview of various methods and techniques used for studying environmental impacts on cultural heritage}

Cultural heritage is comprised of a great variety of materials including buildings, monuments, pigments and art objects. Thus analytical data are essential for determining the state of conservation of the object, as well as the causes and mechanisms of its deterioration. The analytical methods used in this field of research are identical with those used at the cutting edge of modern science. Techniques developed for advanced physics and chemistry can apply to both of ancient and modern materials, since problems encountered in both the advanced technology and cultural heritage areas are similar. However, there is one essential difference between the analysis of ancient and modern materials, since an art or ancient object cannot be replaced and the consumption or damaging of even a small part of it for analytical purposes must be undertaken only where vital data cannot otherwise be obtained. Thus, a significant number of different modern instrumental methods for cultural heritage characterization are available and they have already been used for the investigation of the weathering effects of air pollution on them, supplying us with information on morphology, chemical composition and structure of the materials present in the monument, archaeological artifact, or art object. Depending on the information required and the procedure involved, the analysis can be considered destructive or nondestructive and it can be carried out on the bulk or the object surface. In addition, the obtained data can be panoramic or sequential and the measurements can be directly performed on the work itself or on a sample, depending on the instrumental technique used. In any case, however, one should aim at the maximization of information and the minimization of the consumed volume of the cultural object.

Materials characterization generally includes determination of chemical composition, of crystalline and molecular structure and of morphology of the object under investigation (A. Doménech-Carbó et al., 2009).

The major instrumental methods used for characterizing the chemical composition of the object either in layers or/and in its bulk include: (i) spectroscopic (e.g., XRF, AAS, ICP-AES, Mössbauer spectroscopy) or/and spectrometric techniques (e.g., ICP-MS, LA-ICP-MS), which have been widely used in the identification and determination of major, minor and trace-elements composing either inorganic or organic type cultural objects. The provided information and the application of each specific technique depends on the range of electromagnetic radiation and the phenomenon involved in its interaction with the materials present in the analyzed object (A. Doménech-Carbó et al., 2009; Jenkins, 2000; Putzig et al., 1994); (ii) activation methods (e.g., NAA, PAA), which are based on the interaction of the object material with (fast) neutrons or protons and provide information about the major, minor and trace element composition of the art and archaeological object, which, in turn, can be used to establish their provenance and temporal origin (A. Doménech-Carbó et al., 2009). Concerning the characterization of the crystalline and molecular structure of cultural goods, the analytical techniques most frequently used are grouped into diffraction methods (XRD), spectroscopic (e.g., UV-VIS, FTIR, DRIFT, ATR, FTIR-PAS, Raman, NMR, EPR) and spectrometric methods (e.g., MS, DTMS, DPMS, MALDI), chromatographic methods and thermoanalytical methods (e.g., TG, DTA, DSC) (A. Doménech-Carbó et al., 2009; Jenkins, 2000; Putzig et al., 1994).

The majority of instrumental methods which yield morphological, topological and textural information of objects are mostly microscopy techniques (e.g., light microscopy (LM), 
electron microscopy (SEM, ESEM, TEM) and atomic force microscopy (AFM)) (A. Doménech-Carbó et al., 2009). By using light microscopy (either the low-magnification or the high-magnification technique), characteristics of materials such as the percentage of aggregates, pores, temper or specific minerals, pore or grain size and grain shape as well can be determined, allowing for a better analysis and interpretation of composition, technology, provenance, deterioration and conservation. In addition, the use of electrons instead of light in these instruments permits the characterization of the finest topography of the object surface and additional analytical information can be obtained. The AFM maps the topography of a substrate by monitoring the interaction force between the sample and a sharp tip attached to the end of a cantilever, so that the morphology of the surface of the studied solid sample can be reproduced at nanometer resolution (A. Doménech-Carbó et al., 2009). In addition, whenever a more elaborate surface analysis is pursued, methods based on the interaction of the incident energy provided by a microbeam of photons, electrons, or particles with the atoms or molecules located in the surface of the object sample are used. In such studies, the concept of "surface" should not considered in a strict sense, since the investigation concerns a depth in the range of a few $\mu \mathrm{m}$ on the solid surface. Such surface analysis techniques most frequently used in the characterization of cultural objects include high-resolution spatially resolved microspectroscopes, such as micro-FTIR ( $\mu$ FTIR), microRaman ( $\mu$ Raman), laser-induced breakdown spectroscopy (LIBS), micro-XRF ( $\mu$ XRF), XPS, PIXE, etc (A. Doménech-Carbó et al., 2009; Giakoumaki et al., 2007; Jenkins, 2000; Putzig et al., 1994).

It is worthy of noting that the time-resolved versions of the previous spectroscopic methods (TRS), although it is not new, has opened up a wide range of nascent application areas, including test and measurement in materials characterization. Though the basic technique differs little from the traditional spectroscopic methods, it allows us to measure the temporal dynamics and the kinetics of photophysical processes. The advantage of TRS over traditional spectroscopy is that it enables scientists to make more exact measurements of a sample's properties (Bhargava and Levin, 2003; Isnard, 2006; Miliani et al., 2010; Osticioli et al., 2009; Putzig et al., 1994; Quellette, 2004).

In what follows some representative examples of various analytical techniques commonly used in this field are reported for a better understanding of the particular contribution of each method used.

- FTIR-studies in materials decay: Infrared radiation is usually defined as that electromagnetic radiation whose frequency is between $\sim 14300$ and $20 \mathrm{~cm}^{-1}$ (namely, 0.7 and $500 \mu \mathrm{m}$ ). Within this region of the electromagnetic spectrum, chemical compounds absorb IR-radiation providing there is a dipole moment change during a normal molecular vibration, molecular rotation, molecular rotation/vibration, or a lattice mode or from combination, difference and overtones of the normal molecular vibrations. The frequencies and intensities of the IR-bands exhibited by a chemical compound uniquely characterize the material and its IR-spectrum can be used to identify and quantify the particular substance in an unknown sample. Thus, FTIR and $\mu$ FTIR-spectroscopy is useful for the study of degradation forms of cultural heritage, as it permits to identify the degradation phases and to establish the structural relationship between them and the substrate. A representative example of application of this method concerns the results obtained on marble from a Roman sarcophagus, located in the medieval cloister of St. Cosimato Convent in Rome (Italy) and on oolitic limestone 
from the façade of St. Giuseppe Church in Syracuse (Sicily). The IR-spectra of these samples showed the presence of degradation products composed of calcium sulphate hydrate, commonly called gypsum $\left(\mathrm{CaSO}_{4} \cdot 2 \mathrm{H}_{2} \mathrm{O}\right)$ and calcium oxalate, as well as the presence of organic matter probably due to conservation materials. The qualitative distribution maps of degradation products, obtained by means of micro-FTIR ( $\mu$ FTIR) operating in ATR-mode, revealed that the degradation process is present deep inside the stones also if it is not visible macroscopically (La Russa et al., 2009).

- $\quad$ SEM-studies in deterioration of glass: Deterioration of glass includes both chemical and structural changes. The initial stage of attack is a process that involves ion-exchange between alkali ions, which are present in the silicate structure of the glass, such as $\mathrm{Na}$, $\mathrm{K}$, and hydrogen from the environment. This leads to the formation of a leached or socalled "gel layer" in which alkaline elements are depleted. In case of atmospheric attack, the leached ions will interact with components from the ambient air such as carbon dioxide and sulphur dioxide which will lead to a crust formation including products such as a calcite $\left(\mathrm{CaCO}_{3}\right)$ and gypsum $\left(\mathrm{CaSO}_{4} \cdot 2 \mathrm{H}_{2} \mathrm{O}\right)$ (Adriaens, 2005).

- A combination of stereo-microscope, XRD and ICP-OES techniques was used (Elgohary, 2008) for the investigation of stone degradation due to air-pollution in Amman citadel of Liwān. The whole investigation and specific measurements showed that the damage produced on the surfaces of various calcareous stone samples of this region, either being physical or chemical, such as crustation, crystallization, dirties accumulations and other deteriorating forms, was essentially the result of the synergistic action of rain water and the various gaseous pollutants at prevailed in the region under study.

\section{Gas chromatographic instrumentation for studying the impacts of air pollution on cultural heritage}

\subsection{A brief overview of gas chromatographic techniques}

Chromatography is a separation method that combines separation and analysis. It is wellknown that chromatographic separations are based on physicochemical processes such as diffusion, adsorption and chemical equilibrium of the studied solutes distributed among the mobile and the stationary phase. Gas chromatography (GC) is a technique that is used not only to separate substances from each-other, but also to study physicochemical properties. Some of these properties measured are concerned with the moving gaseous phase, giving emphasis on the determination of the properties of the solutes; for instance, diffusion coefficients of solutes into the carrier gas. Gas chromatographic analysis suffers from the socalled broadening factors, the majority of which is related to non-fulfilment of the assumptions under which the central chromatographic equation embraced by Van Deemter is derived; namely, the non-negligible axial diffusion of the solute gas in the chromatographic column, the non-linearity of the distribution (e.g. adsorption) isotherm and the non-instantaneous equilibration of the solute distribution among the mobile and the stationary phase. However, through these broadening factors gas chromatography is capable of making physicochemical measurements, which lead to very precise and accurate results, by using relatively cheap instrumentation and very simple experimental arrangements. Among the most widely used gas chromatographic methods for physicochemical measurements are the traditional techniques of elution development, frontal analysis and displacement development under constant gas flow-rate (Cazes, 2009). 
The majority of gas chromatographic physicochemical measurements has been done by the inverse gas chromatography (IGC) technique, which uses the same experimental procedures employed in direct gas chromatography, but it focuses its interest on the stationary phase and its behavior towards known probe solutes; for instance, the catalytic properties of the solid stationary phase for reactions between gases. As in direct GC, the results used in IGC to derive information about the physicochemical properties of the stationary phase are based on net retention volumes, broadening of elution peaks and further on the analysis of the statistical moments of the peaks. The usual inverse gas chromatography (IGC), having the stationary phase of the system as the main object of investigation, is an integration method and not a time-resolved chromatography, since it totally ignores the heterogeneity of the adsorbing solid surface, it does not take into account the non-linearity of isotherms, the non-negligible axial diffusion in the chromatographic column and the kinetics of mass transfer across the gas/solid boundary (Cazes, 2009; Katsanos \& Karaiskakis, 2004; Thielmann, 2004).

All the afore-mentioned chromatographic systems are not usually in true equilibrium during the retention period, so that extrapolation to infinite dilution and zero carrier-gas flow-rate is required to approximate true equilibrium parameters. Moreover, they have not a time-resolved character of the experimental procedure, since they provide measurements for physicochemical properties statistically weighed over time and enclosed by the chromatographic elution peaks; some of these properties are indeed independent of time, but there are other properties strongly dependent on the time variable. A new version of IGC is a flow perturbation method, the so-called Reversed-Flow Inverse Gas Chromatography (RF-IGC), which has been introduced in 1980 by N. A. Katsanos et al., and since then it is extensively used as a tool to study various physicochemical processes (Katsanos, 1988; Katsanos \& Karaiskakis, 2004). It is a differential method depending neither on retention times and net retention volumes, nor on broadening factors and statistical moments of the elution bands. In addition, the results of RF-IGC do not need extrapolation to infinite dilution and zero carrier gas flow rate to approximate true physicochemical parameters. All the determinations achieved by RF-IGC are based on rate measurements over an extended period of time, thus constituting a time-resolved chromatography (Katsanos \& Karaiskakis, 2004).

\subsection{The novel method of RF-IGC: physical description and experimental setup}

The Reversed-Flow Inverse Gas Chromatography (RF-IGC) method: (i) abandons the main role of carrier-gas in classical gas chromatography and substitutes it with gaseous diffusion currents inside a new diffusion column perpendicular to the conventional chromatographic current (sampling column), the latter being a little far from the solid bed in which all the desired physicochemical phenomena take place in the absence of gas running; (ii) by means of a four or six port valve the direction of carrier-gas flow is reversed from time to time for short time intervals, thus creating extra narrow chromatographic peaks which are deposited onto the conventional chromatographic signal. All the above described are schematically presented in Figs. 2 and 3. By introducing these modifications, the carrier gas flow does not intervene with the measurement of the desired physicochemical quantities, which describe step by step the entire physicochemical phenomena taking place inside the diffusion column where no carrier gas flows but only a static pressure of it exists. 


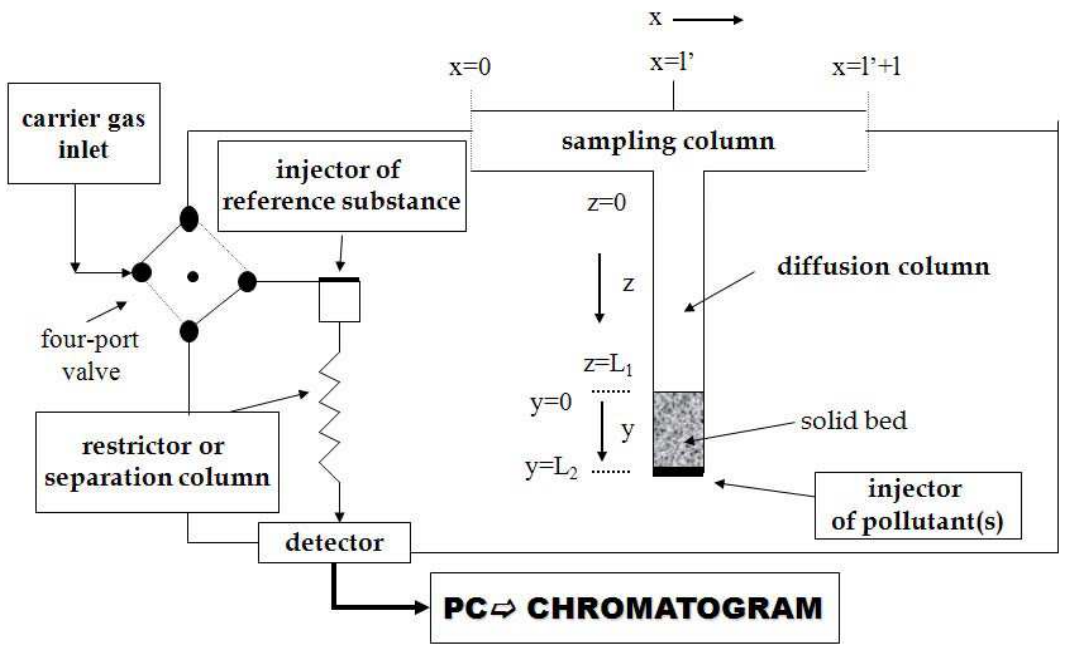

Fig. 2. Experimental setup of RF-IGC

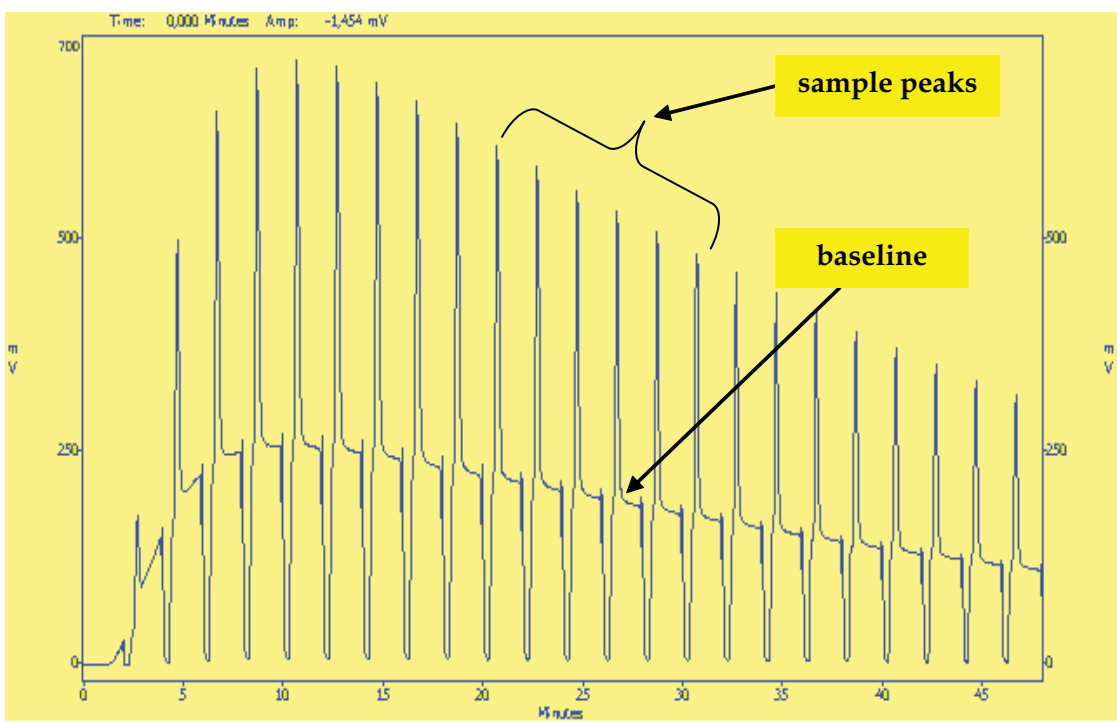

Fig. 3. A typical chromatogram obtained by RF-IGC

The extra chromatographic peaks (Fig. 3) obtained by repeatedly reversing the carrier gas direction for short time intervals are termed sample peaks, because they constitute samples of the phenomena taken from the region of their occurrence at various times, like small samples taken from a reaction occurring in a usual chemical flask containing the reactants. They have different heights depending on the time at which each flow reversal was made. Since this happens at various chosen times, it constitutes a time-resolved experiment like those in chemical kinetics. The experimental details by means of which the reversals are 
effected are shown in Fig. 2. From the series of the sample peaks obtained under various conditions, several physicochemical quantities have been determined and published (Agelakopoulou et al., 2009; Arvanitopoulou et al., 1994; Bakaoukas et al., 2005; Floropoulou et al., 2009; Katsanos et al., 1998,2003,2004; Metaxa et al., 2009a,2009b,2009c; RoubaniKalantzopoulou, 2004,2009; Roubani-Kalantzopoulou et al., 1996; Sotiropoulou et al., 1995). The sample peaks are predicted theoretically by the so-called chromatographic sampling equation (1), which describes the concentration-time curve of the sample peaks created by the flow reversals and has been derived using mass balances, rates of change, etc., and integrating the resulting partial differential equations under given initial and boundary conditions. It gives the concentration of the solute at the junction of the sampling and the diffusion column $x=1^{\prime}$ or $z=0$ of Fig. 2 , for different values of the time variable. The sampling equation predicts the sample peaks theoretically and its predictions coincide with the experimental sample peaks shown in Fig. 3, the only difference being that the peaks predicted are square, whereas those actually found are not square owing obviously to nonideality. In fact, the experimental peaks can be made as narrow as we want, since the width at their half-height is equal to the duration of the carrier-gas flow reversal. The equation describing the height, $H$, of the sample peaks as a function of time, $t$, when each flowreversal was made has the form:

$$
H^{1 / M}=g \cdot c\left(l^{\prime}, t\right)=\sum_{i} A_{i} \exp \left(B_{i}, t\right)
$$

where $i$ runs from $1-4, M$ is the response factor of the detector used ( $M=1$ for a flame ionization detector), $g$ is the calibration factor of the detector (in $\mathrm{cm}^{4} \cdot \mathrm{mol}$ ), $c\left(l^{\prime}, t\right)$ is the measured sampling concentration of the gaseous analyte (in $\mathrm{mol} \cdot \mathrm{cm}^{-3}$ ) at $x=l^{\prime}$ or $z=0$ of Fig. 2 , and $A_{i}, B_{i}$ are functions of the physicochemical quantities pertaining to the various phenomena occurring in the solid bed region. The detailed content of $A_{i}$ and $B_{i}$, as found from a non-linear least-square analysis of the plot of $H^{1 / M}$ versus time $t$, leads to the clear determination of the physicochemical quantities of the mathematical model used; for instance, catalytic reaction constants, adsorption-desorption rate constants, gas and surface diffusion coefficients, local adsorption isotherms, local adsorption energies, local adsorption energy probability density functions, local lateral molecular interactions and adsorption rates, as will be explained for the action of various gaseous pollutants on calcareous stones, marbles and statues in the next sections. In addition, a brief account of the general principles which construct the mathematical model of the method of RF-IGC will be given in the following section.

\subsubsection{Mathematical model}

The theoretical analysis for the measurement of the time resolved physicochemical parameters by RF-IGC is based on the following equations:

i. two mass balances for the gaseous concentration of the analyte in the regions $y$ and $z, c_{y}$ $\left(\mathrm{mol} \cdot \mathrm{cm}^{-3}\right)$ and $c_{z}\left(\mathrm{~mol} \cdot \mathrm{cm}^{-3}\right)$, respectively;

$$
\frac{\partial c_{y}}{\partial t}=D_{2} \frac{\partial^{2} c_{y}}{\partial y^{2}}-k_{-1} \frac{a_{S}}{a_{y}}\left(c_{S}^{*}-c_{S}\right)-k_{a p p} c_{y}
$$




$$
\frac{\partial c_{Z}}{\partial t}=D_{1} \frac{\partial^{2} c_{Z}}{\partial z^{2}}-k_{a p p} c_{Z}
$$

ii. one rate of change of the adsorbed concentration $c_{S}\left(\mathrm{~mol} \cdot \mathrm{g}^{-1}\right)$ of the analyte in the region $y$ and

$$
\frac{\partial c_{S}}{\partial t}=k_{-1}\left(c_{S}^{*}-c_{S}\right)-k_{2} c_{S}
$$

iii. one local adsorption isotherm, which correlates the adsorbed equilibrium concentration $\mathrm{CS}^{*}\left(\mathrm{~mol} \cdot \mathrm{g}^{-1}\right)$ on the solid surface with the non-adsorbed concentration $\mathrm{c}_{\mathrm{y}}$ :

$$
c^{*}=\frac{m_{S}}{a_{S}} \delta\left(y-L_{2}\right)+\frac{a_{y}}{a_{S}} k_{1} \int_{0}^{t} c_{y}(\tau) d \tau
$$

$k_{a p p}$ : is the apparent rate constant of a first- or pseudofirst-order reaction of the gaseous adsorbate in the gas phase (in $\mathrm{s}^{-1}$ ).

$D_{2}$ : is the diffusion coefficient of this gaseous adsorbate into the gas phase in section $y$ (in $\left.\mathrm{cm}^{2} \mathrm{~s}^{-1}\right)$.

$k_{-1}$ : is the rate constant for desorption of the solute from the solid bulk (in s-1).

$c_{S}$ : is the adsorbed concentration of the gaseous adsorbate adsorbed on the solid at time $t$ (in mol g-1).

$k_{2}$ : is the rate constant of a possible first-order or pseudofirst-order surface reaction of the adsorbed solute (in s-1).

With the initial conditions $c_{y}(0, y)=\frac{m}{a_{y}} \delta\left(y-L_{2}\right)$, and $c_{S}(0, y)=0, m$ being the amount (mol) of the gaseous adsorbate introduced as a pulse at $y=L_{2}$, all the required adsorption parameters are calculated from the experimental data - pairs $(H, t)$ and various geometrical characteristics of the diffusion column and the solid bed - on the basis of the following equations, by means of a suitable PC-program based on non-linear least-squares regression analysis (Agelakopoulou et al., 2009; Arvanitopoulou et al., 1994; Bakaoukas et al., 2005; Floropoulou et al., 2009; Katsanos et al., 1998,2003,2004; Metaxa et al., 2009a,2009b,2009c; Roubani-Kalantzopoulou, 2004,2009; Roubani-Kalantzopoulou et al., 1996; Sotiropoulou et al., 1995):

a. local adsorption energies, $\varepsilon$

$$
\varepsilon=R T\left[\ln (K R T)-\ln (R T)-\ln K^{0}\right]
$$

b. local adsorption equilibrium concentrations, $c_{s}^{*}$ and $c_{y}$

$$
\begin{gathered}
c_{s}^{*}=\frac{\alpha_{y}}{\alpha_{s}} k_{1} \frac{v L_{1}}{g D_{z}} \sum_{i=1}^{3} \frac{A_{i}}{B_{i}}\left[\exp \left(B_{i} t\right)-1\right] \\
c_{y}=\frac{v L_{1}}{g D_{1}} \sum_{i=1}^{3} A_{i} \exp \left(B_{i} t\right)
\end{gathered}
$$


c. local adsorption isotherm, $\theta_{t}$

$$
\begin{gathered}
\theta_{t}=\frac{c_{s}^{*}}{c_{s \max }^{*}} \\
\theta=1-\frac{1}{c_{s \max }^{*}} \cdot \frac{1}{K R T} \cdot \frac{\vartheta c_{s}^{*}}{\vartheta c_{y}}
\end{gathered}
$$

d. local monolayer capacity, $c_{s \max }^{*}$ :

$$
c_{s \max }^{*}=c_{s}^{*}+\frac{\partial c_{s}^{*} / \partial c_{y}}{K R T}
$$

e. probability distribution function for adsorption energy, $\varphi(\varepsilon ; t)$ :

$$
\varphi(\varepsilon ; t)=\frac{\theta}{c_{s \max }^{*} R T}\left[\frac{K R T\left(\partial c_{s}^{*} / \partial t\right)+\partial^{2} c_{s}^{*} / \partial c_{y} \partial t}{\partial(K R T) / \partial t}-\frac{\partial c_{s}^{*} / \partial c_{y}}{K R T}\right]
$$

f. dimensionless parameter, $\beta$, for lateral interactions:

$$
z \omega=\beta R T
$$

where: $\omega$ is the lateral interaction energy, $z$ the number of neighbors for each adsorption site and $\beta$ is a dimensionless parameter. Thus, the " $\theta z \omega$ " is the added to $\varepsilon$ "differential energy of adsorption due to lateral interactions", namely:

$$
\theta z \omega=\beta \theta R T
$$

All these relations are based on the Jovanovic local isotherm Eq. (15):

$$
\theta(p, T, \varepsilon)=1-\exp (-K p)
$$

where

$$
K=K^{0}(T) \exp (\varepsilon / R T)
$$

$R$ being the gas constant, and

$$
K^{0}=\frac{h^{3}}{(2 \pi m)^{3 / 2}(k T)^{5 / 2}} \cdot \frac{v_{S}(T)}{b_{g}(T)}
$$

where: $m$ is the molecular mass of the adsorbate; $k$ is the Boltzmann's constant; $h$ the Planck's constant; and the ratio $u_{\mathrm{s}}(T) / b_{\mathrm{g}}(T)$ of two partition functions, namely that of the adsorbed molecule, $u_{\mathrm{s}}(T)$, and that for rotations-vibrations in the gas phase $b_{\mathrm{g}}(T)$. This ratio is taken as a unity, approximately, as was done before (Agelakopoulou et al., 2009; Arvanitopoulou et al., 1994; Bakaoukas et al., 2005; Floropoulou et al., 2009; Katsanos et al., 
1998,2003,2004; Metaxa et al., 2009a,2009b,2009c; Roubani-Kalantzopoulou, 2004,2009; Roubani-Kalantzopoulou et al., 1996; Sotiropoulou et al., 1995).

The contribution of lateral molecular interactions in the overall phenomenon of adsorption and desorption is taken into account, by correcting Eq. (16) to include this type of energy:

$$
K^{\prime}=K^{0} \exp \left(\frac{\varepsilon}{R T}+\beta \theta_{i}\right)=K \exp \left(\beta \theta_{i}\right)
$$

Thus, Jovanovic isotherm described in Eq. (15), is modified accordingly, as well as any other equation based on it.

\subsubsection{Applications of RF-IGC in studying physicochemical phenomena being responsible for materials' decay}

The differential time-resolved RF-IGC method provides a new pathway for solids characterization, by supplying us with experimental local values of important physicochemical quantities, such as adsorption energy, adsorption isotherm, monolayer capacity, non-adsorbed concentration of gaseous analyte in equilibrium with the solid surface, probability density function and energy owing to lateral molecular interactions, which pertain to the particular surfaces. It is reminded that the term "local" means "with respect to time $t^{\prime \prime}$, namely it regards only adsorption sites active at time $t$.

In the following sections, some representative results are described, which have already published in high impact International Scientific Journals and announced in Scientific Symposiums, concerning cultural heritage monuments in Greece (Agelakopoulou et al., 2009; Arvanitopoulou et al., 1994; Bakaoukas et al., 2005; Floropoulou et al., 2009; Katsanos et al., 1998,2003,2004; Metaxa et al., 2009a,2009b,2009c; Roubani-Kalantzopoulou, 2004,2009; Roubani-Kalantzopoulou et al., 1996; Sotiropoulou et al., 1995).

\subsubsection{The local character of adsorption in materials decay: chemisorption or physisorption?}

Due to their different crystallographic properties, natural stones exhibit different types of structural surfaces-each one with its own adsorption energy distribution function-which determines the variations in the observed weathering, deterioration patterns and processes of these materials. The adsorption of atoms or molecules onto these heterogeneous surfaces may occur either by the formation of strong chemical bonds (chemisorption) or via weaker physical attachment (physisorption) of the adsorbed molecules. It should be noted that although the majority of the reported results regards experiments done at relatively low temperatures, where physisorption is more expected, the structural materials of samples used (e.g., statues from Museums) are energetically upgraded, as a consequence of the whole process they have been undergone from the moment of their natural formation until the moment of their use as materials for creating statues. Thus, in the presence of an aggressive environment a chemisorption process is favorable; by means of RF-IGC experiments, chemisorption is observed taking place in the beginning of the experiments (Agelakopoulou et al., 2009; Floropoulou et al., 2009; Katsanos et al., 1998,2003,2004; Metaxa et al., 2009a,2009b,2009c; Roubani-Kalantzopoulou, 2004,2009). Furthermore, any kind of adsorption process (chemisorption or/and physisorption) takes place in different extent, because of the development of molecular lateral interactions (attractive or/and repulsive) between the adsorbed species, in addition to the adsorbent-adsorbate interactions, the latter being the predominant type of forces characterizing chemisorption. In case of chemisorption, 
the lateral interactions between adsorbates are mostly repulsive, resulting in random topography. The adsorbent-adsorbate interactions leading to chemisorptions are chemical bond forces.

The active sites, where chemisorption takes place, are included in the region $\mathrm{A}$ and correspond on the minima of potential energy of the surface, namely the maxima of adsorption energy. The distribution of the adsorbed molecules on these active sites is random. These sites correspond to high values of coverage $\theta$ and adsorption energy $\varepsilon$. The regions $\mathrm{B}$ and $\mathrm{C}$ include active centers that correspond to adsorption at sites of lower energy, $\varepsilon$ and surface coverage, $\theta$. They are characterized by a patchwise or/and an island topography of the adsorbed molecules and created by weak forces of Van der Waals type between the admolecules. Adsorption sites in B and C are not on a free surface, but they are created through the lateral interactions with molecules have been already adsorbed. When chemisorption is taking place, high adsorption energy values are observed, since they correspond to the minima of the potential energy of the surface. Contrary to this, physisorption entails low adsorption energy values, since it usually corresponds to the maxima of the surface potential (saddle points) [Rudzinski \& Everett, 1992]. The decrease of adsorption entropy values verifies that adsorption occurred. All the above are depicted in Figs. (4a)-(4d). The "topography" of the solid surface is described experimentally through the time-resolved analysis of the energy distribution function $\varphi(\varepsilon ; t)$ versus $t$, where distinguished regions corresponding to different kinds of active sites produced at different times are observed, as the three types of active sites recorded in Figs. (4c) and (5c). The number of distinct peaks recorded corresponds to different kinds of active sites appear and the area under these peaks corresponds to the collection of adsorbed species onto active sites with a definite mean energy value; in fact, this reflects or/and explains the "local" character of adsorption. It is worthy of noting that these results coincide with those extracted with simulation methods for the submonolayer adsorption of argon on the surface of crystalline rutile (Bakaev\& Steele, 1992).

In the absence of $\mathrm{SO}_{2}$, an adsorption-induced surface reconstruction creates new adsorption sites, as it is indicated in Figs. 4 (a, b, d) and Figs. $5(\mathrm{a}, \mathrm{b}, \mathrm{d})$. The above observed surface reconstruction [Agelakopoulou et al., 2009; Floropoulou, 2009; Metaxa et al., 2009a, 2009b] may be attributed to one or more of the following reasons:

i. An entropy increase owing to the close approach of adsorbates in various configurations which increase the surface entropy and unveil new active sites for adsorption on the solid surface [Jansen, 2008].

ii. The creation of sub-surface states which does not affect the surface free-energy [Christmann, 1995].

iii. A co-variation in chemisorption and physisorption so that an equilibrium has been established between adsorption and desorption.

The most possible reason in this case seems to be the entropic one, because of the momentary increment of the adsorption entropy observed in Fig. (4d) as a local maximum, which is followed by a new slight decrease in the adsorption entropy thus confirming the readsorption induced. Obviously, the third kind of active sites observed for the adsorption of $\mathrm{C}_{2} \mathrm{H}_{2}$ on the surface of the statues (L291 of Kavala and L1991 of Philippi), in the absence of $\mathrm{SO}_{2}$, resulted from this surface-reconstruction.; in the presence of $\mathrm{SO}_{2}$, only two different types of active sites are observed, as Fig. (4c) indicates. Although the above-mentioned explanation for this surface reconstruction and readsorption induced concerns, in fact, the formation of islands without attractive interactions [Jansen, 2008], another surface 
reconstruction process which favours the formation of islands due to attractive lateral interactions have been proposed by other researchers (Velasco \& Rezzano, 1999). The latter explanation could be also accepted in our case, in the sense that this island-formation occurs in higher time-values and after $\theta=1$, at saddle-points positions (Roubani-Kalantzopoulou, 2004, 2009; Agelakopoulou et al., 2009; Metaxa et al., 2009a).

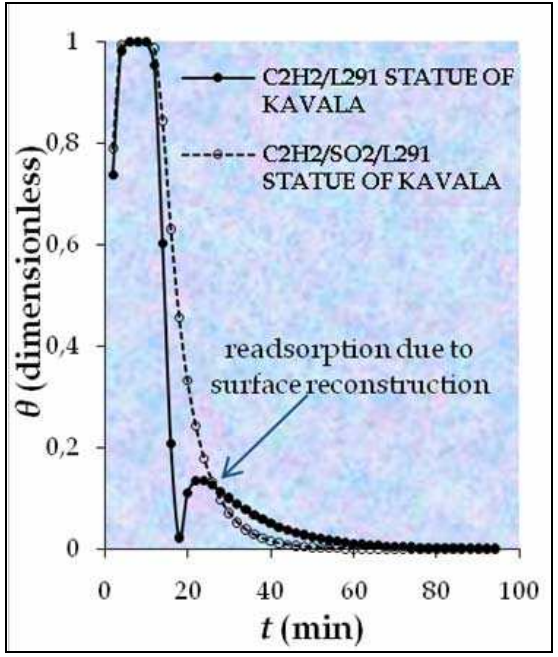

(a)

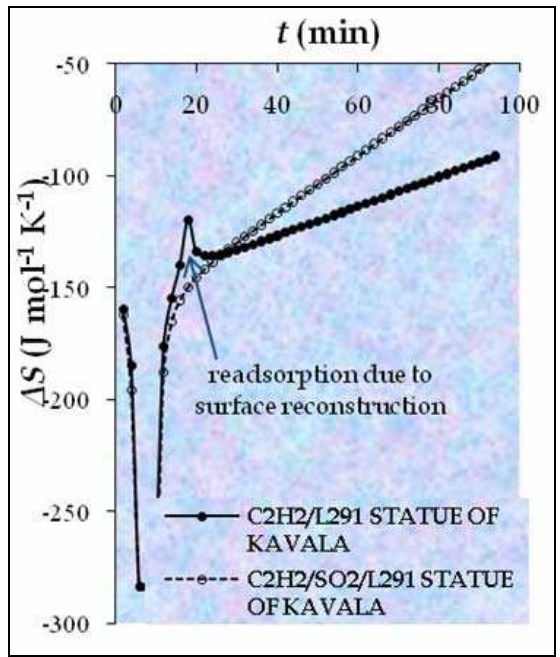

(c)

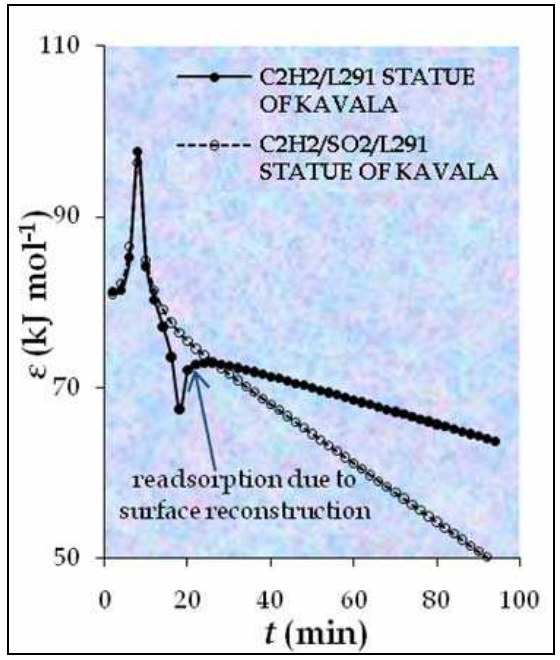

(b)

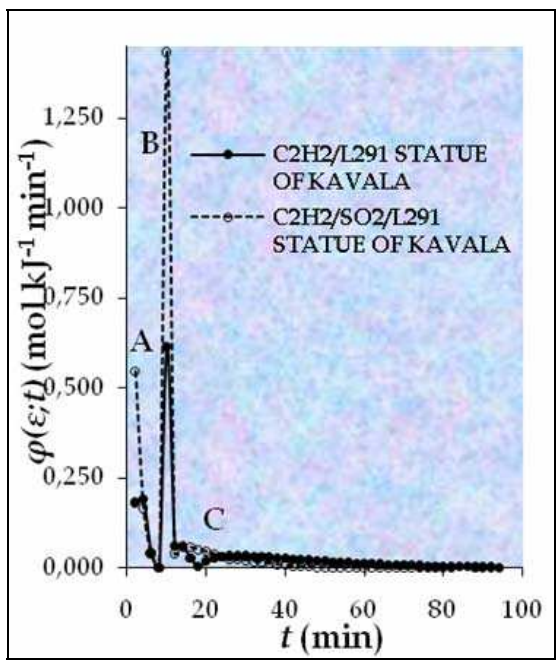

(d)

Fig. 4. Time-resolved analysis for the adsorption isotherms (4a), adsorption energies (4b), distribution energy functions (semi-logarithmic plot) (4c), and adsorption entropies (4d), concerning the systems $\mathrm{C}_{2} \mathrm{H}_{2(\mathrm{~g})} /\left(\mathrm{SO}_{2(\mathrm{~g})}\right) / \mathrm{L} 291$ Statue of Kavala, Greece. 


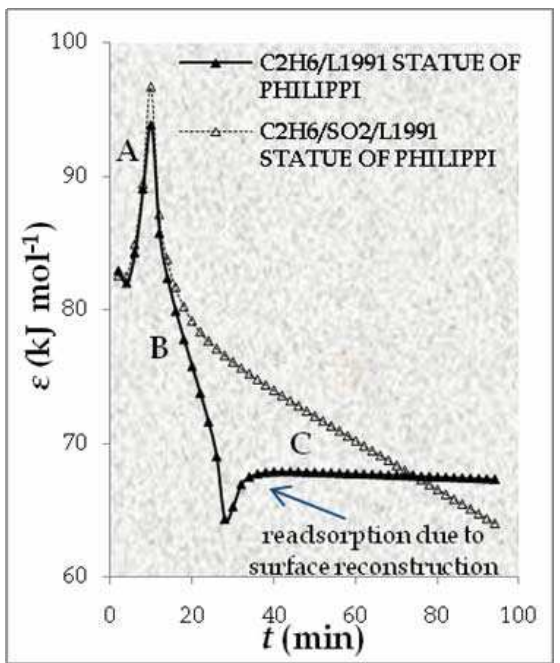

(a)

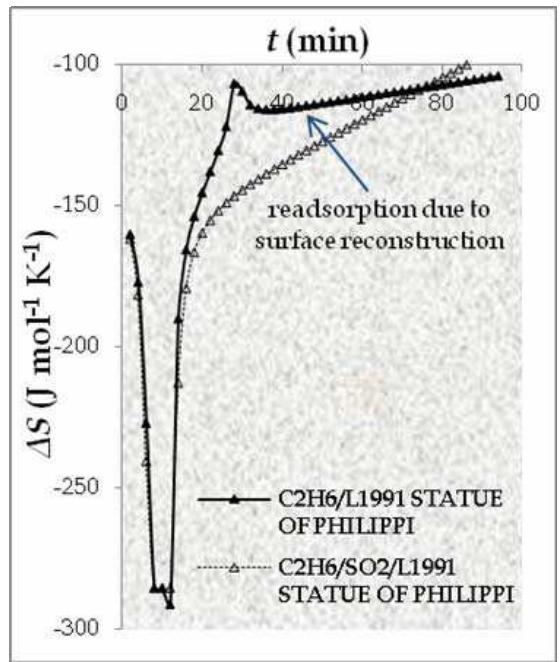

(c)

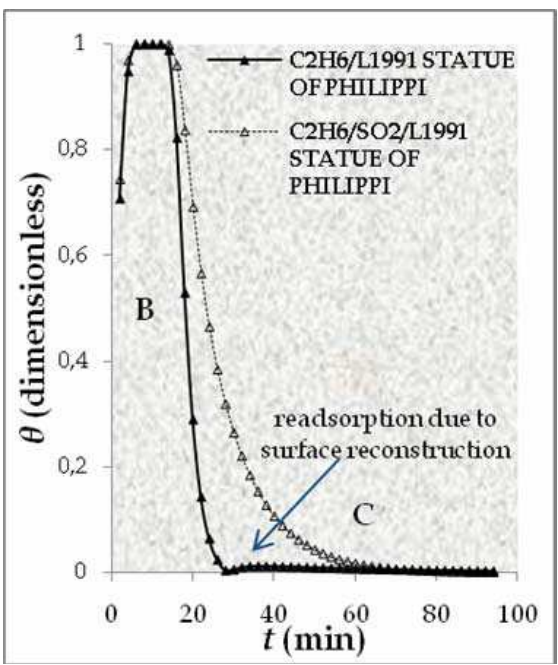

(b)

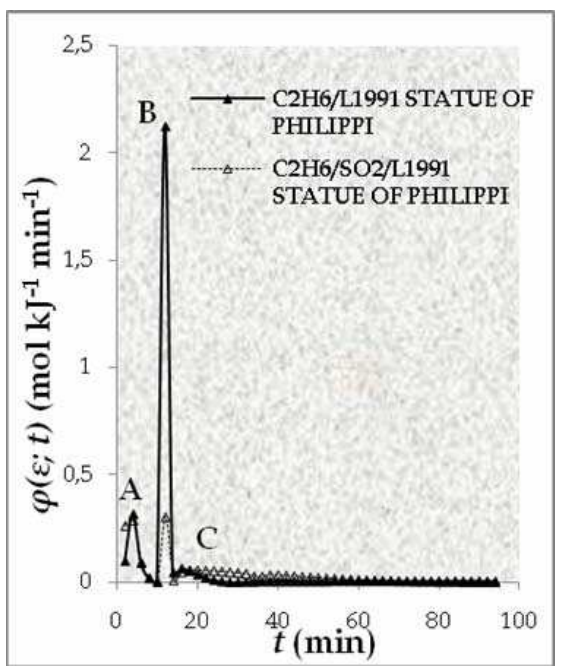

(d)

Fig. 5. Time-resolved analysis for the adsorption isotherms (4a), adsorption energies (4b), distribution energy functions (semi-logarithmic plot) (4c), and adsorption entropies (4d), concerning the systems $\mathrm{C}_{2} \mathrm{H}_{2(\mathrm{~g})} /\left(\mathrm{SO}_{2(\mathrm{~g})}\right) / \mathrm{L} 1991$ Statue of Philippi, Greece.

\subsubsection{The role of synergy in the adsorption phenomena}

The synergistic effect of a second pollutant has also been examined and is very obvious how it operates in each case. For example, in the presence of $\mathrm{SO}_{2}$ lower values for $c^{*}$ ssmax are determined for the adsorption of ethane on the surface of the ancient statue L1991 taken from the interior of the Museum of Philippi, near Salonica, in Greece. This fact could be 


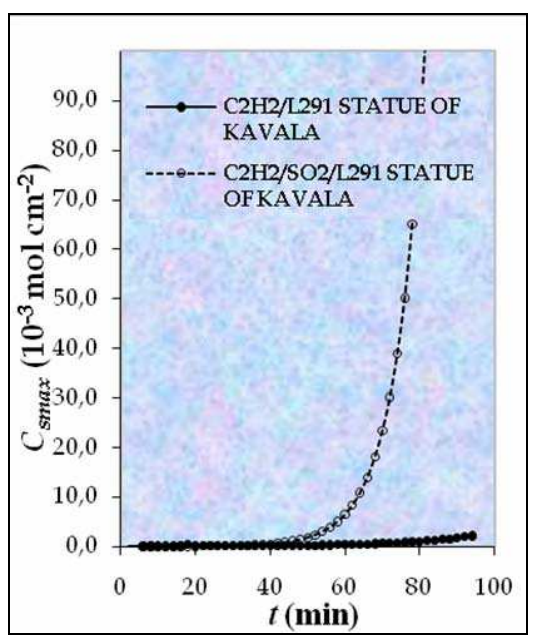

(a)

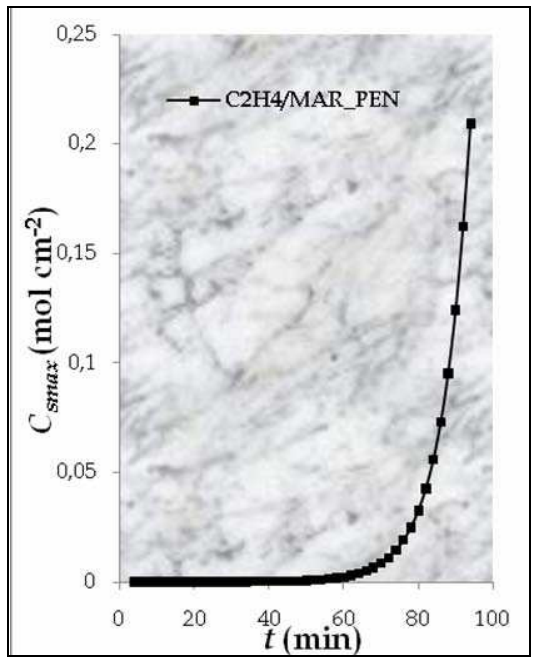

(c)

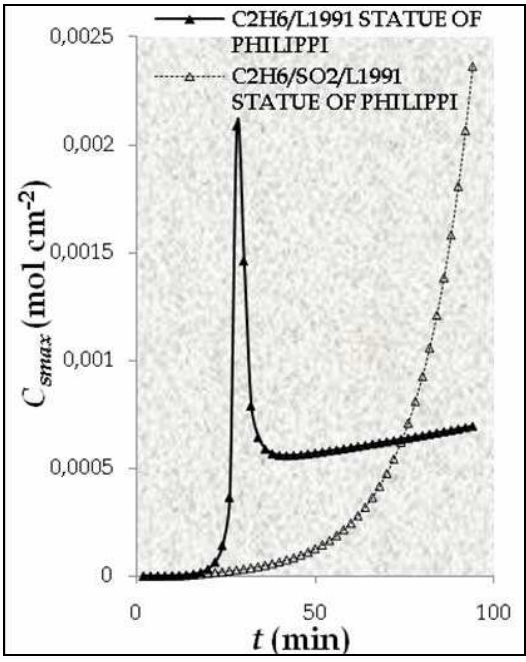

(b)

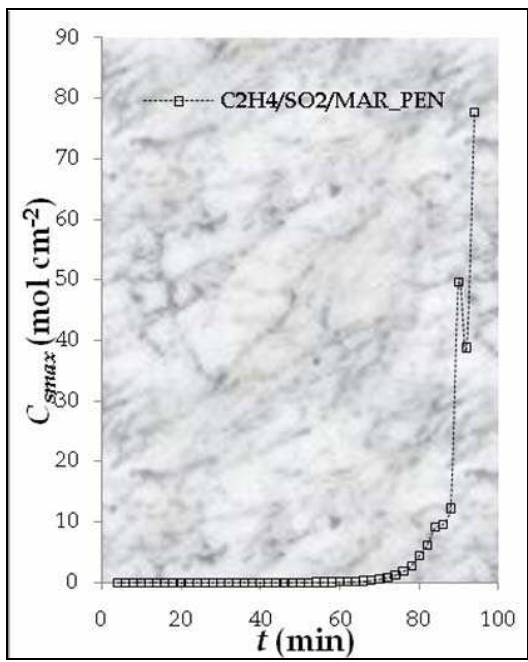

(d)

Fig. 6. Time-resolved analysis of local molecular capacity, $c^{*}{ }_{\text {ssmax }}$, for the systems: (a) $\mathrm{C}_{2} \mathrm{H}_{2} /\left(\mathrm{SO}_{2}\right) / \mathrm{L} 291$ statue of Kavala museum, (b) $\mathrm{C}_{2} \mathrm{H}_{6} /\left(\mathrm{SO}_{2}\right) / \mathrm{L} 1991$ statue of Philippi museum and (c,d) $\mathrm{C}_{2} \mathrm{H}_{4} /\left(\mathrm{SO}_{2}\right) /$ Pentelic marble.

attributed either to an oxidation of the hydrocarbon molecules from $\mathrm{SO}_{2}$ in the gaseous phase before adsorption takes place or to a competitive adsorption of $\mathrm{SO}_{2}$-molecules towards ethane molecules on the active sites of the statue surface. This fact is confirmed by Fig. $5 \mathrm{~d}$, where the number of active sites on the statue surface dramatically decreases in the presence of sulphur dioxide. On the other hand, an opposite behavior is observed concerning the synergistic action of sulphur dioxide on the adsorption of acetylene on the 
surface of the ancient statue L291 - a pure calcite - from the exterior of Kavala Museum and on the adsorption of ethylene on the surface of a recently cut sample from Penteli mountain ore in Dionysos, Greece. The latter is also confirmed by Fig. $4 \mathrm{~d}$, where the number of active sites available for the adsorption of acetylene on the surface of L291 statue increases significantly in the presence of sulphur dioxide. Analogous observations have been drawn for the adsorption of ethane, ethene and ethyne (acetylene) on the surface of another ancient statue sample (L351), which was taken from the interior of the Kavala Museum and it was a pure dolomite, as an X-Ray diffraction analysis of this sample showed. Finally, the amounts of the hydrocarbons which totally adsorbed $\left(\mathrm{c}^{*} \mathrm{~s}\right)$ on both of the statues from Museum of Kavala was calculated, with or without the presence of sulphur dioxide (Agelakopoulou et al, 2009). The results show that with the presence of $\mathrm{SO}_{2}$ an increment of the estimated total adsorbed amount of acetylene is noted for the calcite's statue (L291) of Kavala, contrary to the other hydrocarbons where the presence of sulphur dioxide causes only a negligible or no effect. As regards the dolomite's statue (L351) of Kavala, the synergistic effect of $\mathrm{SO}_{2}$ is more profound. First of all, the totally adsorbed amount of each hydrocarbon on L351 statue, either with or without the presence of sulphur dioxide, is higher than in case of L291 statue, a fact that is ascribable to the higher porosity of the former, which is dolomite, whereas the latter is calcite. Secondly, the higher adsorbed amount found for ethane in the absence of $\mathrm{SO}_{2}$, something is reversed in the presence of $\mathrm{SO}_{2}$ and concerns acetylene. In addition, the synergistic effect of $\mathrm{SO}_{2}$ decreases from acetylene to ethene and ethane; obviously, the order of the bond of hydrocarbon has a significant role in the adsorption phenomenon.

\subsubsection{The influence of the hydrocarbon's bond on the adsorption phenomena}

For the same solid adsorbent (statue, pure oxide, etc.), the influence of the type of the bond in the molecule of the hydrocarbon is related with its molecular weight which reflects on the diffusion coefficient of the molecule. As the molecular weight of the hydrocarbon increases, the corresponding diffusion coefficient decreases. This becomes obvious in the following diagram (Fig. 7) which depicts the non-adsorbed concentration, $c_{y}$, of the hydrocarbon as a function of time $t$ :

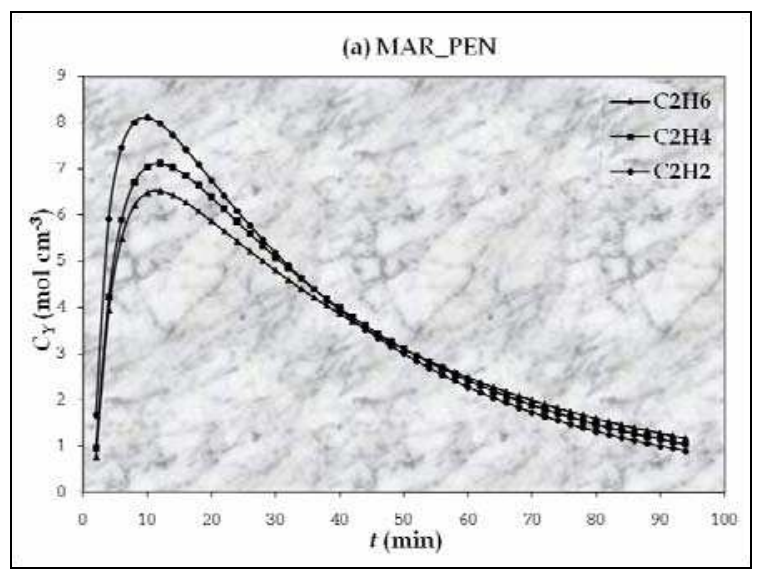

Fig. 7(a). Time-resolved analysis of the local non-adsorbed equilibrium concentration, $c_{y}$, of each hydrocarbon adsorbed on the various solid substrates: (a) marble of Penteli, (b) L1991 statue of Philippi, (c) L291 statue of Kavala and (d) L351 statue of Kavala. 

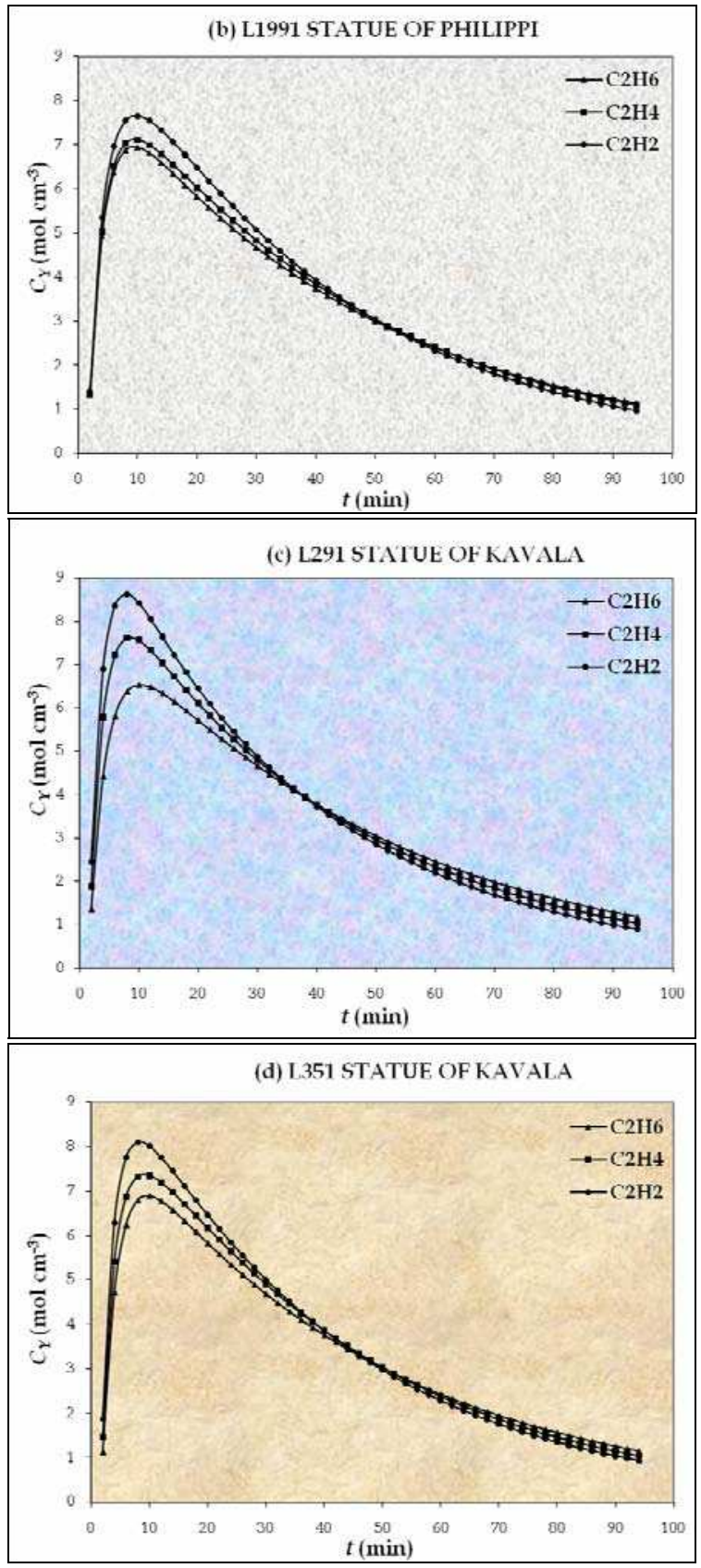

Fig. 7(b, c, d). Time-resolved analysis of the local non-adsorbed equilibrium concentration, $c_{y}$, of each hydrocarbon adsorbed on the various solid substrates: (a) marble of Penteli, (b) L1991 statue of Philippi, (c) L291 statue of Kavala and (d) L351 statue of Kavala. 
4.2.2.4 Characterization of cultural heritage deterioration by means of XRD, SEM and Raman analysis
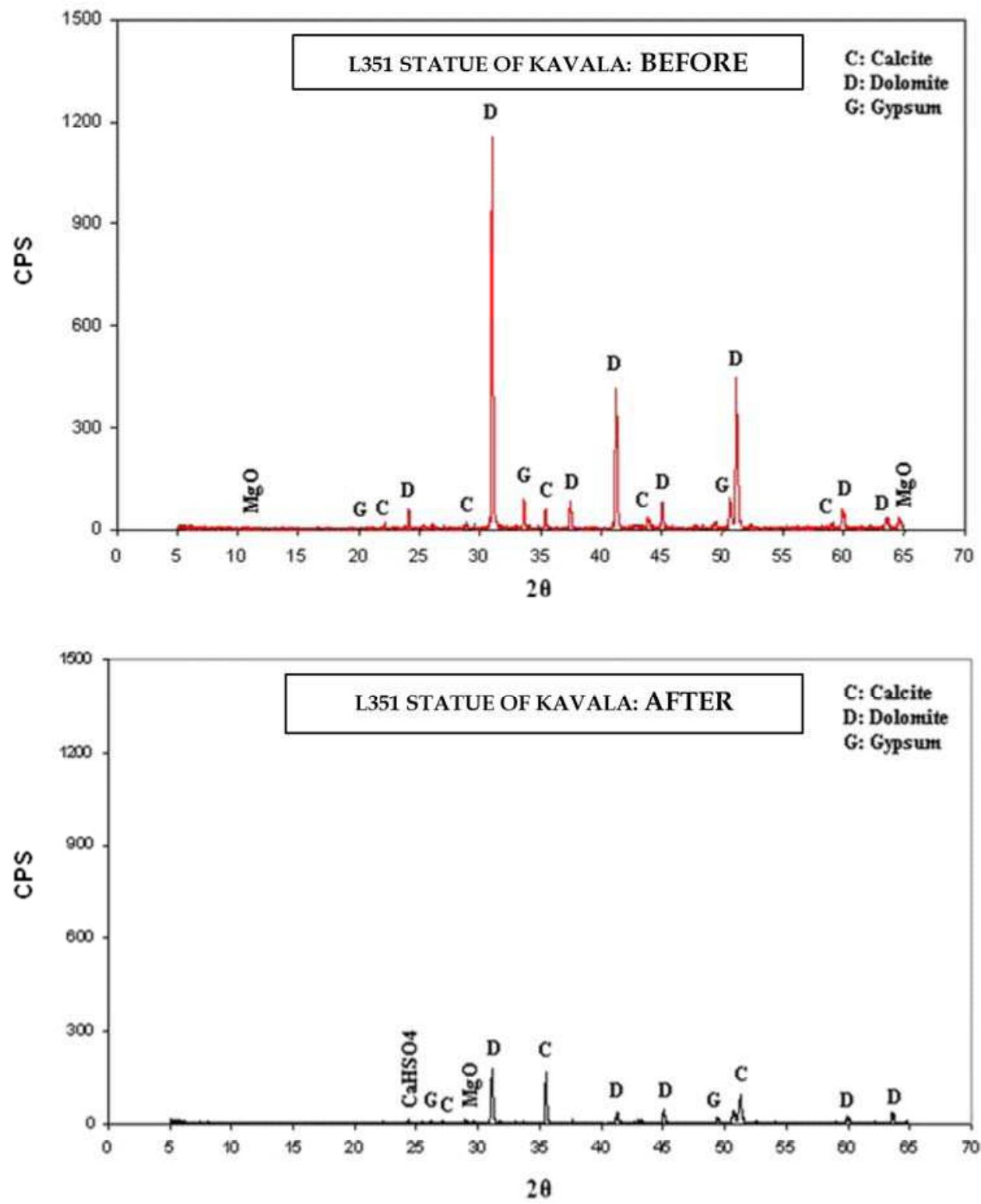

Fig. 8. XRD-diagram for the L351 statue from the interior of the Museum of Kavala: (on the top) before the injection of gaseous pollutants and (at the bottom) after the injection of gaseous pollutants. 
The characterization of the above-mentioned cultural heritage materials through diffraction (XRD), spectroscopic (Raman) and microscopy techniques (SEM) was achieved following to the RF-IGC experiments. For example, the XRD-analysis for the L351 statue from the interior of the Museum of Kavala showed that it is a marble mostly composed of dolomite and quite less of calcite; the opposite stands for the L291 statue from the exterior of the same Museum. As it can also be revealed from the XRD-analysis (c.f. Fig. 8), some gypsum was detected before the exposure of the statue sample to the gaseous pollutants, so either the gypsum was a minor component of the marble or it was formed during a previous exposure of the statue to an atmosphere that permitted this formation. After the exposure to the pollutants, no gypsum was detected by any method used. This is rather expected because there was no humidity during the contact of the injected sulphur dioxide onto the marble. More, an improvement in the organization of the crystallites of the sample is observed after the injection of the gaseous pollutants. In the Raman spectra (c.f. Fig. 9) for the same statue after the exposure an accumulation of weak peaks at $1970-2200 \mathrm{~cm}^{-1}$ is distinguished owing to acetylene $\left(\mathrm{C}_{2} \mathrm{H}_{2}\right)$. More, the main peak existed in $1095 \mathrm{~cm}^{-1}$, before the exposure to the gaseous pollutants, which concerns the carbonate ion, is absent in the spectrum after the injection of the pollutants. The SEM-images for both statues (L351: dolomite and L1991: calcite) are shown in Fig. 10, where is evident the coarse and porous structure of dolomite. Calcite seems more tight and compact. The combination of Raman and SEM-EDAX analysis showed that $\mathrm{SO}_{2}$ was adsorbed (Metaxa et al., 2009b).

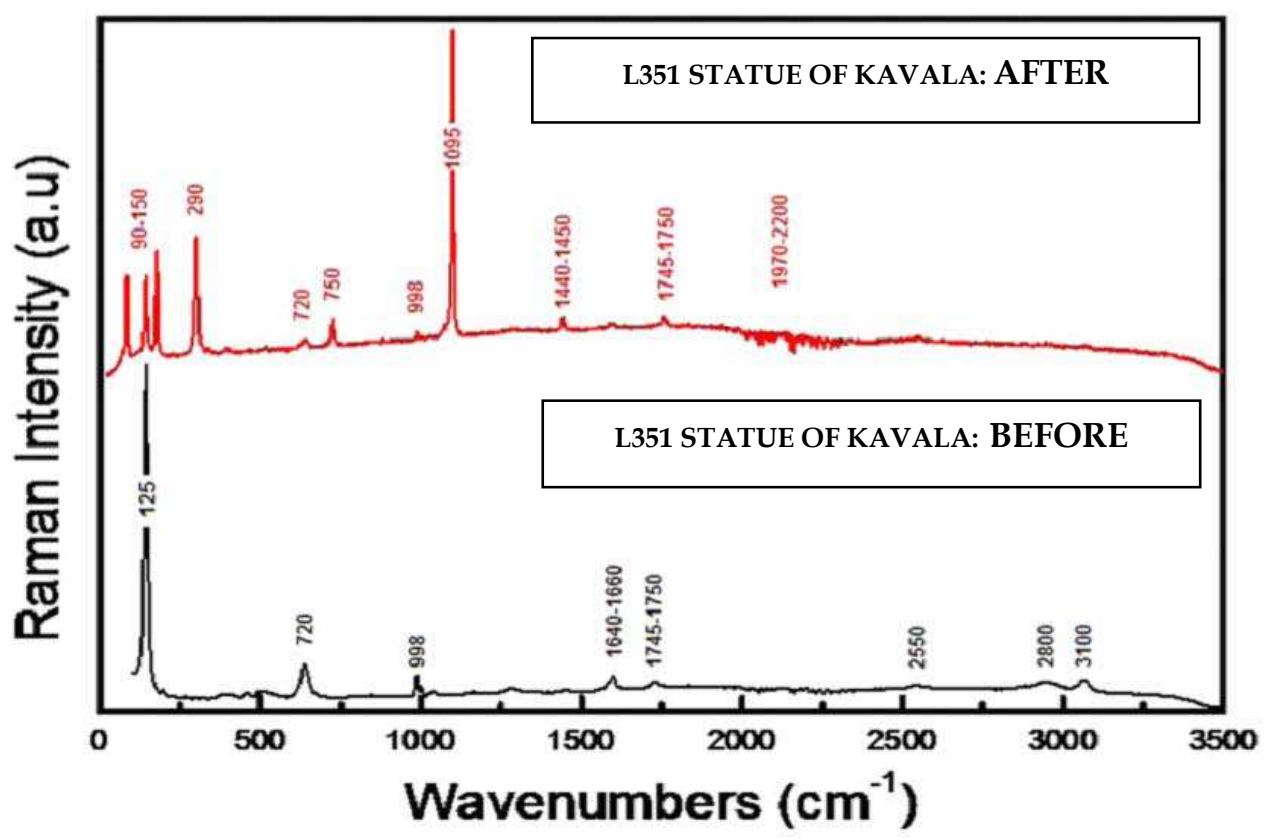

Fig. 9. Raman-spectra for the L351 statue from the interior of the Museum of Kavala: (on the top) before the injection of gaseous pollutants and (at the bottom) after the injection of gaseous pollutants. 


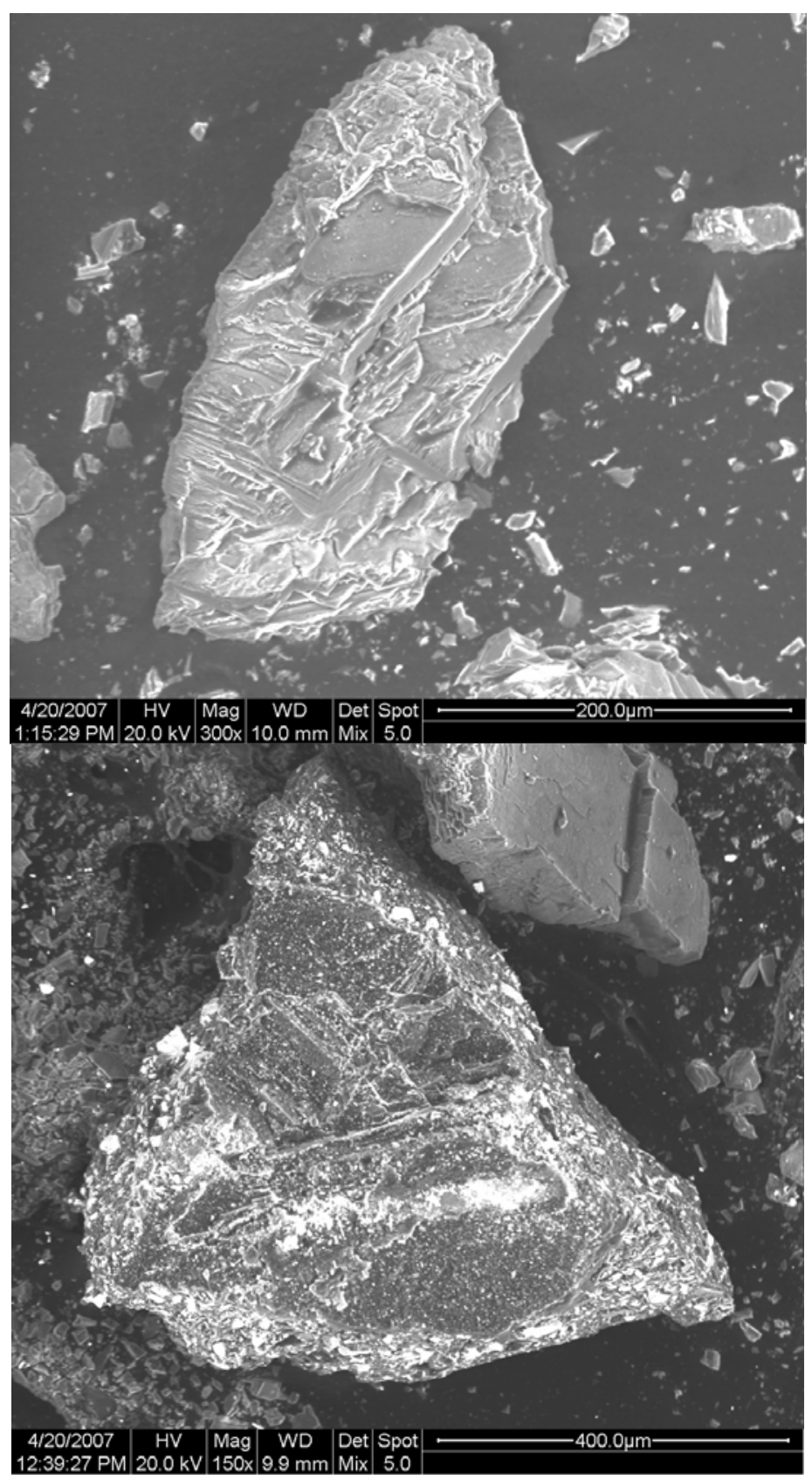

Fig. 10. SEM-images showing the shapes of calcite (on the top) and dolomite (at the bottom). 


\subsubsection{Extracting information about surface heterogeneity}

The "non-ideal" behavior of a solid surface in the direction of the adsorption of a gaseous substance on it consists of an inherent energetic heterogeneity component and an adsorption-induced heterogeneity component originated from the lateral interactions between the adspecies. Surface heterogeneity is responsible for the time-variation in the activation of the various active sites onto the solid surface towards the adsorption process. The effects of surface heterogeneity on adsorption equilibrium have extensively studied, both experimentally and theoretically. The RF-IGC methodology constantly answers for the role of surface heterogeneity on the adsorption phenomena, through the local physicochemical quantities determined for various adsorption systems. The results obtained are in a good agreement with literature data as it has already been shown (Metaxa et al., 2009a).

\subsubsection{Study of the action of sulfur dioxide on Penteli marble in the presence or the absence of protective materials-evaluation of the effectiveness of the protective materials for monuments against sulfur dioxide corrosion}

Calcareous stones, such as marble, suffer from the attack of sulfur dioxide in polluted atmospheres because of the transformation of calcite-content $\left(\mathrm{CaCO}_{3}\right)$ into gypsum $\left(\mathrm{CaSO}_{4} \cdot 2 \mathrm{H}_{2} \mathrm{O}\right)$ as final product [Elgohary, 2008]. The choice of the repair materials is a crucial point in stone conservation. Such operations, in fact, are much critical, as they can alter the structure of the original material and create new textural heterogeneity at the natural stone-composite interface. In order to avoid unsuccessfully results, the characteristics of materials used in conservation works and their compatibility, including long-term effects, with existing materials should be fully established. Thus, new impregnation products, as well as those which already exist, must be viewed with caution and be subjected to laboratory research before they applied on historic buildings. The choice between "traditional" and "innovative" materials and techniques should be determined case-by-case with preference given to those that are least invasive and most compatible with heritage values, consistent with the need for safety and durability.

Protective materials, such as acrylic copolymers and siloxanes, have been largely used in conservation practice as coatings, consolidants and adhesives, because of their good adhesion, film forming properties and their environmental stability. These materials alter the physicostructural properties of the porous materials and change the physicochemical behavior of the interface between the work of art and the environment [Carreti \& Dei, 2004]. Therefore, the characterization of the solid surfaces before and after the application of these materials is important for the evaluation of their ability to protect the historic monuments and buildings.

In order to study the action of $\mathrm{SO}_{2}$ on Penteli marble, experiments were carried out by using the RF-IGC instrumentation and various physicochemical parameters (rate constants as well as equilibrium constants) were calculating by using a non-linear regression analysis PCprograms in GW-BASIC [Katsanos et al., 2003] for the experimental data. Afterwards, kinetic parameters such as adsorption rate constants $k_{1}$, adsorption/desorption $k_{R}$ and surface reaction rate constants $k_{2}$, as well as surface diffusion coefficients $D_{y}$, deposition velocities $V_{d}$ and reaction probabilities $\gamma$ of $\mathrm{SO}_{2}$ "on marble surfaces, at various temperatures," in the presence or in the absence of protective materials (an acrylic copolymer, Paraloid B-72 or a siloxane, CTS Silo 111) were calculated and discussed 
[Bakaoukas et al., 2005]. The results showed that both materials are good enough at low temperatures (303.2-323.2K), while at high temperatures (333.2-353.2K) siloxane acts better as protective material than acrylic copolymer. More specifically, the values of surface reaction rate constant $k_{2}$ in all cases where the marble was coated by the acrylic copolymer were bigger than those for pure marble, while they were smaller in all cases where the siloxane was used as protective material. Probably that happens because $\mathrm{SO}_{2}$ interacts with the acrylic copolymer and not with the siloxane and a mechanism was proposed for this interaction. On the other hand, the values of the adsorption rate constant $k_{1}$ for the system $\left(\mathrm{SO}_{2}+\right.$ marble) were bigger than those for the systems $\left(\mathrm{SO}_{2}+\right.$ coated marble), thus indicating that the adsorption of $\mathrm{SO}_{2}$ is more difficult in the case of coated marble than in the pure marble. In addition, the values of $V_{d}$ and $\gamma$ in most cases where the marble was coated with anyone of the protective materials were smaller than those for pure marble, except from the higher temperature of $353.2 \mathrm{~K}$ where the differences before and after coating with the acrylic copolymer were negligible; probably, because in this high temperature $\mathrm{SO}_{2}$ interacts more rapidly with the acrylic copolymer. Concerning the effect of coatings on $\mathrm{D}_{\mathrm{y}}$-values, it was found that in the absence of protective materials, at extreme temperatures $(>333.2 \mathrm{~K})$, the porous of the marble is being destroyed producing surface diffusion coefficients equivalent to diffusion coefficients in the gas phase. On the contrary, in the presence of protective materials, the later does not happen due to the shrink of the porous size of the marble[Bird et al., 2002; Carreti \& Dei, 2004; Bakaoukas et al., 2005].

\section{Conclusions}

Among the various causes which are responsible for the destruction of cultural property, namely of historic artifacts and monuments, air pollution could be considered as an important one. Cultural goods are chiefly significant as a kind of evidence of past human activity. Conservation of cultural heritage allows this evidence to be consulted whenever new questions about the past are emerged. Thus it is well-understood that successful conservation has to be underpinned by a comprehensive understanding of the causes of decay and the factors controlling them.

In order to estimate the impacts of air pollution on the various solid surfaces, including them of cultural heritage, in a real scientific basis, theory and experiment needs to cooperate in a way close to real systems. From this aspect of view, the new dynamic version of classic inverse gas chromatography, the so-called Reversed-Flow Inverse Chromatography (RFIGC), combining a powerful mathematical background with a very simple and smart experimental arrangement, attains this purpose by using time-resolved analysis in the way this method has developed it. Thus, by means of a simple PC-program, important local physicochemical quantities are determined, which characterize the main rate processes taking place at the phase boundaries, such as adsorption and desorption, aiming at their spreading in the bulk. Lately, this method has been successfully applied to the study of the impact of air pollutants on many cultural heritage objects, such as marbles, pigments of works of art, etc., by studying the topography of active sites in heterogeneous solid surfaces and their availability for adsorption, without using retention volume data, as it abandons the traditional role of the carrier gas in conventional chromatography and substitutes it with gaseous diffusion currents. The results of this method are based on a non-linear adsorption isotherm model and rate measurements over an extended period of time. All the 
chromatographic methods known up to now offer approximate functions for the probability density function for the adsorption energy, without any determination of local adsorbed parameters, as this technique does. All findings supplied from the application of this methodology in various systems gas/solid provide valuable information about the susceptibility of the examined artifact or statue to environmental gaseous pollutants.

\section{References}

Adriaens, A. (2005). Review: Non-destructive Analysis and Testing of Museum Objects: An Overview of 5 Years of Research. Spectrochimica Acta Part B, Vol. 60, pp. 1503-1516.

Agelakopoulou, T.; Metaxa, E.; Karagianni, Ch.-S. \& Kalantzopoulou-Roubani, F. (2009). Air Pollution Effect of $\mathrm{SO}_{2}$ and/or Aliphatic Hydrocarbons on Marble Statues in Archaeological Museums. Journal of Hazardous Materials, Vol. 169, pp. 182-189.

Arvanitopoulou, E.; Katsanos, N.A.; Metaxa, H. \& Roubani-Kalantzopoulou, F. (1994). I. Simple Measurement of Deposition Velocities and Wall Reaction Probabilities in Denuder Tubes-II. High Deposition Velocities. Atmospheric Environment, Vol. 28, No. 15 , pp. 2407-2412.

Bakaev, V.A. \& Steele, W.A. (1992). Computer Simulation of the Adsorption of Argon on the Surface of Titanium Dioxide. 1. Crystalline Rutile. Langmuir, Vol. 8, No. 5, pp. 13721378.

Bakaoukas, N.; Kapolos, J.; Koliadima, A. \& Karaiskakis, G. (2005). New Gas Chromatographic Instrumentation for Studying the Action of Sulfur Dioxide on Marbles. Journal of Chromatography A, Vol. 1087, pp. 1693-176.

Bhargava, R. \& Levin, I.W. (2003). Time-Resolved Fourier Transform Infrared Spectroscopic Imaging. Applied Spectroscopy, Vol. 57, No. 4, pp. 357-366.

Bird, R.B.; Stewart, W.E. \& Lightfoot, E.N. (2002). Transport Phenomena (2nd ed.), Wiley, ISBN:0471410772, New York.

Carreti, E. \& Dei., L. (2004). Physicochemical Characterization of Acrylic Polymeric Resins Coating Porous Materials of Artistic Interest. Progress in Organic Coatings, Vol. 49, No. 3, pp. 282-289.

Cazes, J. (2009-10-12). Encyclopedia of Chromatography (3rd ed.), CRC Press, ISBN: 1420084593, U.S.A.

Christmann, K. (1995). Some General Aspects of Hydrogen Chemisorption on Metal Surfaces. Progress in Surface Science, Vol. 48, No. 1-4, pp. 14-26.

Doménech-Carbó, A.; Doménech-Carbó, M.T. \& Costa, V. (2009). Chapter 1: Application of Instrumental Methods in the Analysis of Historic, Artistic and Archaeological Objects, In: Electrochemical methods in archaeometry, conservation and restoration (1 ${ }^{\text {st }}$ ed.), Scholtz Fritz (ed.), pp. 1-32, Springer-Verlag, ISBN: 978-3-540-92867-6, Berlin.

Elgohary, M.A. (2008). Air Pollution and Aspects of Stone Degradation "Umayyed LiwānAmman Citadel as a Case Study". Journal of Applied Sciences Research, Vol. 4, No. 6, pp. 669-682.

Giakoumaki, A.; Melessanaki, K. \& Anglos, D. (2007). Review: Laser-Induced Breakdown Spectroscopy (LIBS) in Archaeological Science-Applications and Prospects. Analytical \& Bioanalytical Chemistry, Vol. 387, No. 3, pp. 749-760.

Isnard, O. (2006). In Situ and/or Time Resolved Powder Neutron Scattering for Materials Science. Journal of Optoelectronics and Advanced Materials, Vol. 8, No. 2, pp. 411-417. 
Jansen, A.P.J. (2008). Island Formation without Attractive Interactions. Physical Reviews B, Vol. 77, No. 7, article: 0732408, 4 pages.

Jenkins, R. (2000). X-Ray Techniques: Overview, In: Encyclopedia of analytical chemistry, Meyers, R.A. (eds.), pp. 1-20, John Wiley \& Sons Ltd, ISBN: 9780470027318, U.S.A.

Katsanos, N.A., (1988). Flow Perturbation Gas Chromatography (1'st ed.), Marcel Dekker, New York-Basel.

Katsanos, N.A.; Thede, R. \& Roubani-Kalantzopoulou, F. (1998). Review: Diffusion, Adsorption and Catalytic Studies by Gas Chromatography. Journal of Chromatography A, Vol. 795, pp. 133-184.

Katsanos, N.A.; Gavril, D. \& Karaiskakis, G. (2003). Time-Resolved Determination of Surface Diffusion Coefficients for Physically Adsorbed or Chemisorbed Species on Heterogeneous Surfaces, by Inverse Gas Chromatography. Journal of Chromatography A, Vol. 983, No. 1, pp. 177-193.

Katsanos, N.A. \& Karaiskakis, G. (2004). Time-Resolved Inverse Gas Chromatography and its Practical Applications (1st ed.), HNB Publishing, ISBN: 0-9728061-0-5, New York.

La Russa, M.F.; Ruffolo, S.A.; Barone, G.; Crisci, G.M.; Mazzoleni, P. \& Pezzino, A. (2009). The Use of FTIR and micro-FTIR Spectroscopy: an Example of Application to Cultural Heritage. International Journal of Spectroscopy, Vol. 2009, pp. 1-5.

Metaxa, E.; Kolliopoulos, A.; Agelakopoulou, T. \& Kalantzopoulou-Roubani, F. (2009a). The Role of Surface Heterogeneity and Lateral Interactions in the Adsorption of Volatile Organic Compounds on Rutile Surface. Applied Surface Science, Vol. 255, pp. 64686478.

Metaxa, E.; Agelakopoulou, T.; Bassiotis, I.; Karagianni, Ch. \& Kalantzopoulou-Roubani, F. (2009b). Gas Chromatographic Study of Degradation Phenomena Concerning Building and Cultural Heritage Materials. Journal of Hazardous Materials, Vol. 164, pp. 592-599.

Metaxa, E.; Agelakopoulou, T.; Karagianni, Ch.-S. \& Kalantzopoulou-Roubani, F. (2009c). Study of the Adsorption of Ozone on the Surface of Ferric Oxide by Revered-Flow Inverse Gas Chromatography. Instrumentation Science \& Technology, Vol. 37, No. 5, pp. 584-606.

Miliani, C.; Rosi, F.; Brunetti, B.G. \& Sgamelloti, A. (2010). In Situ Noninvasive Study of Artworks: the MOLAB Multitechnique Approach. Accounts of Chemical Research, Vol. 43, No. 6, pp. 728-738.

Osticioli, I.; Mendes, N.F.C.; Porcinai, S.; Cagnini, A. \& Castellucci, E. (2009). Spectroscopic Analysis of Works of Art Using a Single LIBS and Pulsed Raman Setup. Analytical E Bioanalytical Chemistry, Vol. 394, No. 4, pp. 1033-1041.

Putzig, C.L.; Leugers, M.A.; McKelvy, M.L.; Mitchell, G.E.; Nyquist, R.A.; Papenfuss, R.R. \& Yurga, L. (1994). Infrared spectroscopy. Analytical Chemistry, Vol. 66, No. 12, pp. 26R-66R.

Quellette, J. (2004). Time-Resolved Spectroscopy Comes of Age. The Industrial Physicist, 2, pp. 16-19.

Roubani-Kalantzopoulou, F.; Metaxa, H.; Kalantzopoulos, A.; Kalogirou, E.; Sotiropoulou, V. \& Katsanos, N.A. (1996). Contribution to the Mechanism of Marble Deterioration by Gas Chromatographic Studies, Koutsoukos, P. \& Kontoyiannis, Ch. (Eds.), Eurocare-Euromarble EV496 Workshop 7, Patras, Greece, October 1996, pp. 33-38. 
Roubani-Kalantzopoulou, F. (2004). Review: Determination of Isotherms by Gas-Solid Chromatography Applications. Journal of Chromatography A, Vol. 1037, No. 1-2, pp. 191-221.

Roubani-Kalantzopoulou, F. (2009). Review: Time-Resolved Chromatographic Analysis and Mechanisms in Adsorption and Catalysis. Journal of Chromatography A, Vol. 1216, No. 10, pp. 1567-1606.

Sotiropoulou, V.; Vassilev, G.P.; Katsanos, N.A.; Metaxa, H. \& Roubani-Kalantzopoulou, F. (1995). Simple Determination of Experimental Isotherms Using Diffusion Denuder Tubes. Journal of the Chemical Society Faraday Transactions, Vol. 91, pp. 485-492.

Thielmann, F. (2004). Review: Introduction into the Characterization of Porous Materials by Inverse Gas Chromatography. Journal of Chromatography A, Vol. 1037, No. 1-2, pp. $115-123$. 


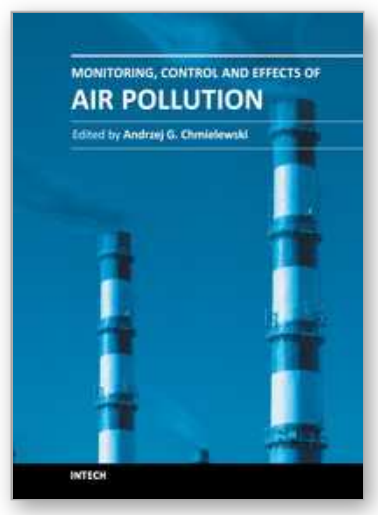

\author{
Monitoring, Control and Effects of Air Pollution \\ Edited by Prof. Andrzej G. Chmielewski
}

ISBN 978-953-307-526-6

Hard cover, 254 pages

Publisher InTech

Published online 23, August, 2011

Published in print edition August, 2011

The book addresses the subjects related to the selected aspects of pollutants emission, monitoring and their effects. The most of recent publications concentrated on the review of the pollutants emissions from industry, especially power sector. In this one emissions from opencast mining and transport are addressed as well. Beside of SOx and NOx emissions, small particles and other pollutants (e.g. VOC, ammonia) have adverse effect on environment and human being. The natural emissions (e.g. from volcanoes) has contribution to the pollutants concentration and atmospheric chemistry governs speciation of pollutants, as in the case of secondary acidification. The methods of ambient air pollution monitoring based on modern instrumentation allow the verification of dispersion models and balancing of mass emissions. The comfort of everyday humanâ $€^{\mathrm{TM}} \mathrm{S}$ activity is influenced by indoor and public transport vehicles interior air contamination, which is effected even by the professional appliances operation. The outdoor pollution leads to cultural heritage objects deterioration, the mechanism are studied and the methods of rehabilitation developed. However to prevent emissions the new technologies are being developed, the new class of these technologies are plasma processes, which are briefly reviewed at the final part of the book.

\title{
How to reference
}

In order to correctly reference this scholarly work, feel free to copy and paste the following:

Eleni Metaxa (2011). Air Pollution and Cultural Heritage: Searching for "The Relation Between Cause and Effect”, Monitoring, Control and Effects of Air Pollution, Prof. Andrzej G. Chmielewski (Ed.), ISBN: 978-953307-526-6, InTech, Available from: http://www.intechopen.com/books/monitoring-control-and-effects-of-airpollution/air-pollution-and-cultural-heritage-searching-for-the-relation-between-cause-and-effect-

\section{INTECH}

open science | open minds

\section{InTech Europe}

University Campus STeP Ri

Slavka Krautzeka 83/A

51000 Rijeka, Croatia

Phone: +385 (51) 770447

Fax: +385 (51) 686166

www.intechopen.com

\section{InTech China}

Unit 405, Office Block, Hotel Equatorial Shanghai

No.65, Yan An Road (West), Shanghai, 200040, China

中国上海市延安西路65号上海国际贵都大饭店办公楼405单元

Phone: +86-21-62489820

Fax: $+86-21-62489821$ 
(C) 2011 The Author(s). Licensee IntechOpen. This chapter is distributed under the terms of the Creative Commons Attribution-NonCommercialShareAlike-3.0 License, which permits use, distribution and reproduction for non-commercial purposes, provided the original is properly cited and derivative works building on this content are distributed under the same license. 